\title{
A confecção de bonecas negras na formação docente
}

Graziela Rinaldi da Rosa ${ }^{1}$, Adriana da Silva Ferreira ${ }^{2}$

${ }^{1}$ Universidade Federal do Rio Grande - FURG. Campus São Lourenço do Sul. Instituto de Educação. Rua Marechal Floriano Peixoto, 2236, Centro. São Lourenço do Sul - RS. Brasil. grazirinaldi@gmail.com.

${ }^{2}$ Universidade Federal do Rio Grande - FURG.

RESUMO. O trabalho artesanal na/com docência tem sido adaptado nas metodologias de pesquisa-ação e história oral e contribuído para diferentes maneiras de pensar o artesanato na formação de professores/as. $\mathrm{O}$ artesanato geralmente é realizado por mulheres e contribui no fortalecimento da identidade, como fonte de renda e valorização dos saberes populares. Foi adotada a metodologia de oficinas com o objetivo de confeccionar bonecas negras, sendo a oficineira uma estudante quilombola. Buscou-se empoderar estudantes, mulheres negras $\mathrm{e}$ quilombolas por meio da confecção dessas bonecas, que simbolizam a identidade negra. Tal prática teve uma repercussão na vida de mulheres e professores/as em formação. Foi possível aprender que a confecção de bonecas negras, embasada por teorias que visam valorizar os povos tradicionais, e aqui especialmente os quilombolas, em diálogo com a educação popular, vai além de uma técnica artística, trata-se de um (re)olhar para si e para as questões étnico-sociais.

Palavras-chave: Mulheres Negras, Identidade Negra, Diversidade na Educação. 


\title{
The confection of black dolls in the teacher education
}

\begin{abstract}
The craft work on/with teaching has been adapted in action research methodologies, it has contributed to different ways of thinking the craft work on teacher education. The craft work is usually made by women and contributes in strengthening the identity as a source of income and appreciation of popular knowledge. It was adopted the workshop methodology in order to make black dolls, with a quilombola student as mediator. It was searched to empower students, quilombolas and black women through the making of these dolls that symbolize the black identity. This practice impacted the lives of women and teachers in formation. It was possible to learn that the confection of black dolls, based on theories that aim to value the traditional people, and here especially the quilombolas, in dialogue with popular education, goes beyond a art technique, it is a (re)look for themselves and the ethnic and social issues.
\end{abstract}

Keywords: Black Women, Black Identity, Diversity in Education. 


\section{La confección de muñecas negras en la formación docente}

RESUMEN. El trabajo artesanal en la/con docencia ha sido adaptado en las metodologías de investigación-acción e historia oral y ha contribuido para distintas formas de pensar el trabajo artesanal en la formación de profesores/as. La artesanía generalmente es realizada por mujeres y contribuye en el fortalecimiento de la identidad, como fuente de ingresos y valoración de los saberes populares. Fue adoptada la metodología de talleres con el objetivo de confeccionar muñecas negras, siendo la tallerista una estudiante quilombola. Se buscó empoderar estudiantes, mujeres negras y quilombolas por medio de la confección de esas muñecas, que simbolizan la identidad negra. Tal práctica tuvo una repercusión en la vida de mujeres y profesores/as en formación. Fue posible aprender que la confección de muñecas negras, basada en teorías que buscan valorar los pueblos tradicionales, y acá especialmente los quilombolas, en dialogo con la educación popular, va más allá de una técnica de arte, se trata de una nueva mirada sobre sí mismo y sobre las cuestiones étnico -sociales.

Palabras-clave: Mujeres Negras, Identidad Negra, Diversidad en la Educación. 


\section{Introdução}

Realizar junto com as mulheres quilombolas e com a comunidade e nas escolas essa atividade que tem como objetivo o resgate da autoestima e a valorização do povo negro desenvolvendo a consciência enquanto se trabalha valores, étnicos raciais construindo o empoderamento para esses indivíduos tantas vezes invisibilizados. Neste momento de construção eu também como mulher negra quilombola me reconheço me identifico com histórias dessas quilombolas, que mesmo sendo de diferentes localidades, cidades ou ate mesmo estados a nossa essência se identifica nos reconhecemos, somos filhas $\mathrm{e}$ de origem iguais. A confecção de bonecas negras são as vozes dos quilombolas durante as oficinas faz com que se pense de forma diferenciada, com metodologia e pesquisa. As bonecas negras podem ser confeccionadas por qualquer pessoa que queira valorizar sua cultura, autoestima, combater $\mathrm{o}$ racismo fazendo se ativo nesta caminhada tão árdua de descriminalização, inferioridade e invisibilidade ainda tão presentes, esses problemas não serão combatidos da noite para o dia, mais com dedicação e luta teremos uma sociedade melhor. Precisamos que os negros/as parem de se desvalorizar se sintam capazes de fazer e atuar em qualquer âmbito de trabalho só que para isso é preciso acreditar e principalmente estudar muito. Por meio do esforço e da capacidade de cada um os grilhões que assombram os negros hoje ainda vão cair por terra. (Ferreira, 2016, s/p).

Este artigo é resultado de algumas práticas escolares e comunitárias desenvolvidas no Curso de Licenciatura em Educação do Campo, da Universidade
Federal do Rio Grande, e de ações desenvolvidas junto à comunidade e povos tradicionais quilombolas, como por exemplo, a "Oficina Bonecas Negras: Resgatando a cultura do artesanato e construindo a identidade negra" realizada pelo Núcleo de Estudos Afro-Brasileiro, Indígena (NEABI-SLS). As oficinas têm sido desenvolvidas por estudantes do curso de Licenciatura em Educação do Campo, coordenadas pela professora da Disciplina de Educação Popular e a acadêmica quilombola, Adriana da Silva Ferreira, estudante do Curso de Licenciatura em Educação do Campo - Ênfase em Ciências da Natureza e Ciências Agrárias da Universidade Federal do Rio Grande FURG, Campus São Lourenço do Sul RS.

A referida oficina compôs as atividades de um projeto de extensão, intitulado "Resistência, Negritudes e Quilombolas: Ouvindo os ecos dos Quilombos do Município de São Lourenço do Sul". Teve como objetivos contribuir com o resgate da cultura do artesanato; debater sobre a potencialidade do brincar com bonecas negras e refletir sobre a construção da identidade do/a negro/a por meio da confecção de bonecas negras de pano, bem como problematizar questões relacionadas ao preconceito e ao racismo, 
buscando pensar/redescobrir/reafirmar a identidade negra.

Tais reflexões desenvolvidas em aulas de Educação Popular e em atividades de extensão rompem com o espaço acadêmico de salas de aulas. Acreditamos que o exercício do artesanato de bonecas negras e a reflexão sobre ele contribui na constituição da identidade negra, pelo fato de reviver e rememorar a cultura negra em suas raízes com o re-olhar para essas mulheres, bem como no fortalecimento étnico racial de suas identidades.

Kleba e Wendausen (2009) afirmam que o processo de empoderamento é dinâmico, e sua produção envolve diferentes aspectos, dentre eles, o cognitivo e o afetivo. Explicam que o objeto deste processo é aumentar o poder da autonomia pessoal e coletiva. Este aumento de poder nas relações visa a construir instrumentos, principalmente para aqueles "submetidos a relações de opressão, discriminação e dominação social". (Kleba \& Wendausen, 2009, p. 736).

Nesse sentido, o empoderamento se constitui ao entender que a ação docente está presente e articulada a artesania, a partir do momento em que se pensa questões como: de que forma e quais as causas que provocam o "não olhar" para as questões étnicos-raciais? $\mathrm{E} \quad \mathrm{O}$ enfraquecimento da identidade negra? Tal trabalho visa problematizar no currículo dos cursos de Licenciaturas em Educação do Campo o lugar dos povos tradicionais quilombolas, e dar visibilidade aos mesmos, trabalhando questões Étnicoraciais em nossos currículos, e dando visibilidade ao trabalho artesanal de mulheres.

Durante essas oficinas é possível estudar sobre feminismos e direitos das mulheres. Quanto à organização do movimento feminista no Brasil, Saffioti (1976, p. 274) destacou que:

\begin{abstract}
Apesar de ter resultado da importação de ideias que não encontravam muito eco na sociedade brasileira (neste sentido, teria, se tivesse tido pleno êxito desde seu início, criado um grande hiato entre a legislação referente à mulher $\mathrm{e}$ as verdadeiras relações sociais que a inferiorizavam), inoculou, em boa parcela das mulheres, a aspiração de libertar-se e de emancipar-se através do trabalho, processo este que foi amadurecendo à medida que, efetivamente, iam os elementos femininos penetrando em áreas até então reservadas exclusivamente aos homens.
\end{abstract}

Soihet (1997, p. 99) "atribui o avanço da abordagem do feminino ao campo da história cultural", visto que temos também a contribuição dos estudos feministas e de gênero que abordam o feminino, histórias de vida e pensamentos de mulheres, que não é uma história à parte da própria história, pois as mulheres escreveram sobre suas vidas e suas 
histórias. Nesse sentido, as bonecas negras “dão vozes" às mulheres dos quilombos, na medida em que possibilitam a partilha e a escuta. Muitas são agricultoras familiares e outras tantas artesãs, que tecem suas histórias em meio ao esquecimento de suas existências.

\section{Sobre os quilombolas do município de São Lourenço do Sul/RS}

Invisíveis, isoladas, com as pessoas trabalhando como empregadas ou sob a forma de meeiro (parceria em que a metade da produção vai para o dono da terra) para os fazendeiros ou colonos vizinhos. Essa era a situação inicial das comunidades. Sem serviços básicos - luz, água -, sofrendo muita discriminação por causa do racismo e sem perspectivas de continuarem na terra, pequena, apertada e sem segurança fundiária. Não participavam dos espaços da agricultura familiar; muitos não tinham documentos, como carteira de identidade. Os jovens, quando podiam, saíam para as cidades para trabalhar, engrossando as estatísticas do êxodo rural e do crescimento das ocupações nas cidades. Não eram reconhecidos como comunidades, mas como um grupo de mão de obra barata e disponível na área rural. Em termos mais amplos, eram simplesmente invisíveis. Não se falava da existência de comunidades negras na região (Dutra, 2011, p. 74).

Essa citação diz respeito às comunidades do território Sul do Rio Grande do Sul. Nela percebemos a precária condição de vida desses sujeitos, e que práticas muito incipientes têm sido desenvolvidas para superar os recorrentes problemas desses povos. Mostra também a invisibilidade desses povos e a necessidade de se trabalhar a autoestima, identidade e respeito, bem como da valorização do conhecimento tradicional.

No município de São Lourenço do Sul temos as Comunidades:

Quilombola da Picada; (2) Comunidade

Quilombola Rincão das Almas; (3)

Comunidade Quilombola Monojolo; (4)

Comunidade Quilombola Torrão e (5)

Comunidade Quilombola Coxilha Negra e

(6) Boqueirão. Conforme publicação do Centro de Apoio ao Pequeno Agricultor (2010), a Comunidade quilombola Picada fica no $3^{\circ}$ distrito de São Lourenço do SulRS, na localidade de Santa Tereza. É composta por 17 famílias, que dividem uma área de 55 hectares. A comunidade de Rincão das Almas está localizada no $5^{\circ}$ distrito do Município de São Lourenço do Sul-RS, composta por 70 famílias. Ocupa uma extensão de 50 hectares de terra. O quilombo Monjolo está localizado em Campo Quevedos, $7^{\circ}$ distrito do município de São Lourenço do Sul-RS, agregando 25 famílias em uma área de 30 hectares. A comunidade quilombola Vila Torrão está localizada no Canta Galo, $7^{\circ}$ distrito do Município de São Lourenço do Sul-RS, composta por 19 famílias que vivem em uma área de sete hectares. Conforme dados de Capa (2010), Coxilha Negra, localidade 
da estudante bonequeira quilombola está localizada no $6^{\circ}$ distrito do município de São Lourenço do Sul, agregando 30 famílias em 55 hectares de terra, sendo 30 hectares com títulos.

Cabe destacar aqui que o conceito "Quilombo" trata do conceito de etnogênese como oposição ao etnocídio dos diversos grupos étnicos que compõem o todo (Arruti, 2005) e não se refere apenas a um local geograficamente definido, historicamente "documentado" e arqueologicamente "escavado". Ele designa um processo de trabalho autônomo, livre da submissão dos grandes proprietários. Não delimitado por um território e isolado apenas, mas capaz de se reverter domínios fundiários reconhecidos pela Lei de Terras de 1850 (Linhares, 2009). Quilombo é um conceito próprio dos africanos bantos que vem sendo modificado através de séculos, "acampamento guerreiro na floresta", sendo entendido em Angola como "divisão administrativa", indicando uma reação guerreira e uma situação opressiva (Leite, 1999).

Os estados brasileiros que se destacam pela concentração de comunidades quilombolas são: Maranhão, Minas Gerais, Bahia e Pará. Conforme Dutra (2011, p. 16), "a existência de quilombos contemporâneos é uma realidade latino-americana. Tais comunidades são encontradas em países como a Colômbia, Equador, Suriname, Honduras, Belize e Nicarágua". Estima-se que no Brasil há cerca de três mil comunidades quilombolas (Dutra, 2011, p. 16). As comunidades quilombolas encontram-se em sua maioria em zonas rurais, mas existem comunidades na zona urbana.

Como se percebe, há um vasto campo de estudos no que diz respeito aos quilombos do Município de São Lourenço do Sul, e cerca de 161 famílias quilombolas para conhecermos, dialogarmos e pensarmos sobre formas de superação de seus problemas.

\section{Lutas, resistências, silenciamentos e invisibilidades}

A importância deste projeto para nós da comunidade quilombolas daqui da cidade de São Lourenço do Sul-RS é de suma importância. Encontros como esse mostram nossas tradições, nossos costumes, muitas vezes esquecidos pela comunidade. Somos lembrados nestas datas que se comemoram o dia da consciência negra - 20 de novembro (Ferreira, 2016, s/p).

Partindo da fala da estudante quilombola, buscamos deixar clara a essência desse trabalho, pois "ouvir os ecos desses povos remanescentes" significa escutar sua história, conhecer sua gente, o seu povo, e ouvir o que eles e elas têm a 
nos ensinar em um movimento simbiótico, capaz de provocar uma ação, que busca a superação do silenciamento e ocultamente desses povos. Chamamos de ecos, pois queremos ouvir aquilo que eles falam e “gritam" nos Quilombos. Queremos ouvir suas músicas, suas danças, conhecer sua culinária, o seu artesanato e contribuir para que esses ecos se transformem em vozes que dão visibilidade para os povos.

Sabemos que os desafios são grandes, mas que estamos inseridos/as em uma cidade que possui comunidades Quilombolas e é nosso compromisso, enquanto professores/as, pesquisadores/as e estudantes da Universidade Federal do Rio Grande (FURG) dialogar e buscar formas de superação dos problemas que essas comunidades quilombolas enfrentam em seu cotidiano. Não estamos nos referindo a práticas que acontecem apenas no mês da Consciência Negra. A comunidade acadêmica tem dialogado com esses povos, comprometidos com a valorização dos mesmos.

O marco do reconhecimento da existência dos quilombos no Brasil se deu em 1988, mas isso não significa que hoje esses povos têm reconhecimento em seu cotidiano. Vejamos a fala da jovem quilombola, do Município de São Lourenço do Sul, residente do Quilombo da Coxilha Negra:
O povo negro ainda nos dias atuais é muito discriminado, o racismo ainda é grande, não aparece com grande força que realmente tem porque ele muitas das vezes é velado. E isto tudo é muito triste, para um país onde mais da metade da população é mestiça, há um grande caminho pela frente para percorrer em busca da igualdade racial e social. (Ferreira, 2016, s/p).

Não é novidade que muitos são os desafios. Podemos destacar a valorização, reconhecimento de sua identidade, valorização de sua cultura, estima e autoconfiança, sem falar na questão fundiária, visto que as áreas que as comunidades quilombolas ocupam hoje são áreas muito limitadas, cercadas nas suas maiorias por grandes fazendeiros e agricultores familiares pomeranos, povos que também possuem um histórico de lutas e resistências.

O povo negro é um povo muito forte só que ele ainda não se deu por conta. Nós, povo negro também devemos nos conscientizar. Não ficarmos mais calados em frente a tantas injustiças e aos constrangimentos racistas que seguidamente toleramos, devemos dar um basta a tudo isto. E não ficarmos somente indignados quando a mídia mostra algum flagrante que algum famoso sofreu. E sim devemos indignarmos e se conscientizar mediante a pobreza do nosso país que em sua maioria é negra, visto que grande parte das pessoas que vivem nas favelas são de origem negra que muita das vezes se tornam traficantes se prostituem, abarrotam os presídios. Em vez de estarem estudando e tendo uma vida honesta e não vivendo flagelados na miséria, 
sem esperança de que não tem mais opções melhores para se viver. Quando nós negros nos unirmos de verdade em busca de reformas, e mais conhecimentos, colocaremos em prática nossos direitos, veremos que ninguém mais pisará sobre nós e daremos um basta ao racismo e a desigualdade racial (Ferreira, 2016, $\mathrm{s} / \mathrm{p})$

Outros/as instituições tem dialogado com esses povos, como podemos observar Dutra (2011, p. 73) onde relata que tanto os quilombolas como as equipes da Fundação Luterana de Diaconia e do Centro de Apoio ao Pequeno Agricultor (CAPA) afirmaram que: "a discriminação e o racismo são um problema real na região e relataram vários episódios ilustrativos de atitudes discriminatórias e racistas. Com isso, a autoestima das pessoas e das comunidades negras estava muito baixa ...”.

Cabe a nós educadores/as da Educação do Campo olhar para o povo tradicional quilombola e criar novas metodologias para dialogar com os mesmos, a fim de contribuir para superação de seus problemas e do preconceito historicamente construído a respeito desses sujeitos e sujeitas!

\section{As bonecas negras como instrumento de empoderamento}

A superação dos problemas de gênero é possível quando as pessoas se dão conta e denunciam as "suas amarras". Nesse sentido, possibilitar momentos de socialização de problemas de gênero que as mulheres enfrentam em seu cotidiano é fundamental para lutarmos por melhores condições de vida. Para diagnosticar demandas e dar vozes às mulheres do campo e da cidade de São Lourenço do Sul foram realizadas atividades onde as mulheres do campo e da cidade de São Lourenço do Sul/RS puderam se conhecer, perceber suas semelhanças, diferenças e dialogar, fortalecendo assim as suas identidades, e se empoderando num movimento dialógico, contribuindo para conhecendo protagonismo das mulheres de São Lourenço do Sul/RS/Brasil (Rosa, 2016, p. 49).

O se permitir pensar como pessoas negras muitas vezes não é permitido na infância. E isso se dá por diferentes motivos: como o medo, o silenciamento, a vergonha, a baixa estima, até o fato de até pouco tempo não existir bonecas negras a venda no comércio e, se existia, o valor era bem maior do que as bonecas brancas.

Além do racismo e dos preconceitos étnico-raciais, o patriarcado é outro sistema de opressão que abordamos nas oficinas, pois ele visa suprir os interesses dos homens, visto que ele ainda está presente em nossas práticas sociais, bem como em nossas formas de nos relacionarmos com os outros. $\mathrm{O}$ patriarcado ainda está infiltrado em quase tudo na nossa sociedade, na maneira que educamos, seja em casa ou nas escolas.

Poucas mulheres questionam sua “inferioridade social” e, além de homens, 
"há um número incalculável de mulheres machistas". (Saffioti, 2004, p. 35). A mulher tem como pré-definidas, em nossa sociedade, algumas características sociais dentro dessa lógica, e uma delas é que "la mujer-madre es transmisora, defensora y custodia del orden imperante em la sociedad y en la cultura. Tanto los rituales domésticos o sociales, como los cuidados, están a cargo de las mujeres y forman parte de su condición histórica". (Lagarde y de los Ríos, 2005, p. 377).

As crianças precisam ter brinquedos como referencial da sua identidade, e que sejam capazes de fortalecer a sua própria autoestima. Como uma criança negra poderá se identificar com uma boneca branca? Como ela poderá criar a sua identidade negra com autoestima?

Com bonecas brancas as meninas e os meninos negros/as não percebem nem um traço parecido com o seu. Seus cabelos são diferentes e não há traços que demarcam a sua ancestralidade.

As bonecas negras são tão importantes quanto os livros de infância que contam as histórias de povos negros e constam personagens negros, contos de matriz africana, entre outros. Além disso, nas Oficinas de Bonecas Negras os meninos rompem com a lógica patriarcal, confeccionando bonecas com as meninas.
Acreditamos que tais práticas contribuem no reconhecimento e comprometimento com suas origens, visto que ainda hoje vemos poucas negras/os com seus cabelos soltos, trançados ou ao natural. Poucas são as mulheres negras que usam turbantes nas ruas. Aprender sobre a cultura dos povos negros pode ajudar a libertar homens e mulheres do desconhecimento de si e dos preconceitos que carregam.

Os estereótipos de corpos brancos também reforçam a identidade não negra, contribuindo para o sentimento de inferioridade, baixa estima e exclusão desses sujeitos/as. Muitos crescem sem se verem como pessoas negras, sem conhecerem suas origens e valorizar culturas e antepassados.

Não se culpe. Provavelmente foram seus pais que lhe ensinaram o que eles também aprenderam. A gente aprende as ideias mais absurdas desde criancinha e nunca parou para analisar seus fundamentos. Como é que pode alguém acreditar que todas as pessoas da sua raça são melhores, mais inteligentes e mais bonitas que todas as pessoas da outra raça? Até numa mesma família, há casos de filhos do mesmo pai e da mesma mãe que são completamente uns dos outros! É por isso que estas teorias racistas, totalmente infundadas, não encontram respostas nas ciências. Não se confundir herança biológica com herança cultural. As teorias racistas se baseiam no "determinismo biológico", que é totalmente falso. A cor da pele, o tipo de cabelo ou o formato do nariz não definem o 
caráter e nem a inteligência das pessoas (Matos, 2004, p. 56).

A oficina de bonecas negras contribuiu para pensar sobre os problemas da população negra e o não conhecimento das comunidades quilombolas, bem como na problematização das políticas públicas para essa população.

Figura I. Oficina de Bonecas Negras realizada na semana Acadêmica integrada da FURG/Campus São Lourenço do Sul.

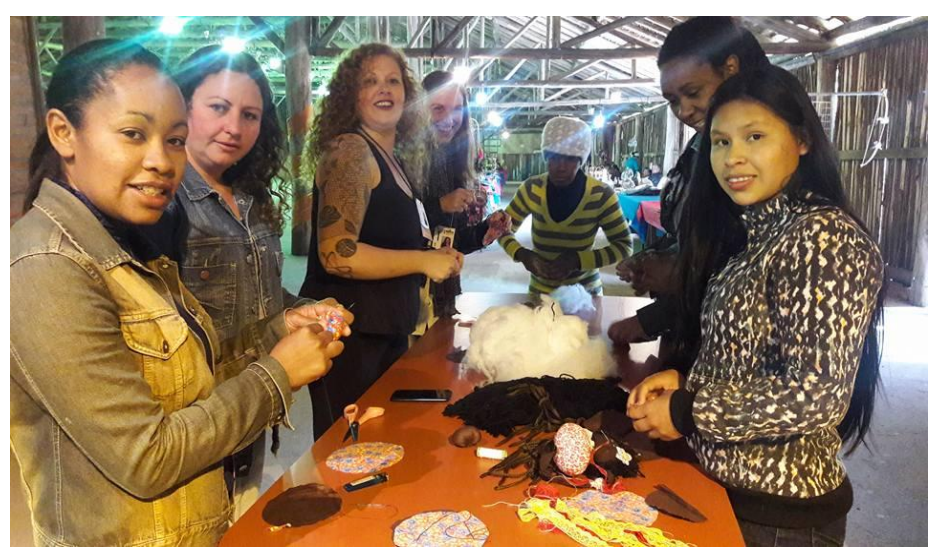

Figura II. Bonecas Negras e estudante quilombola Adriana da Silva Ferreira.

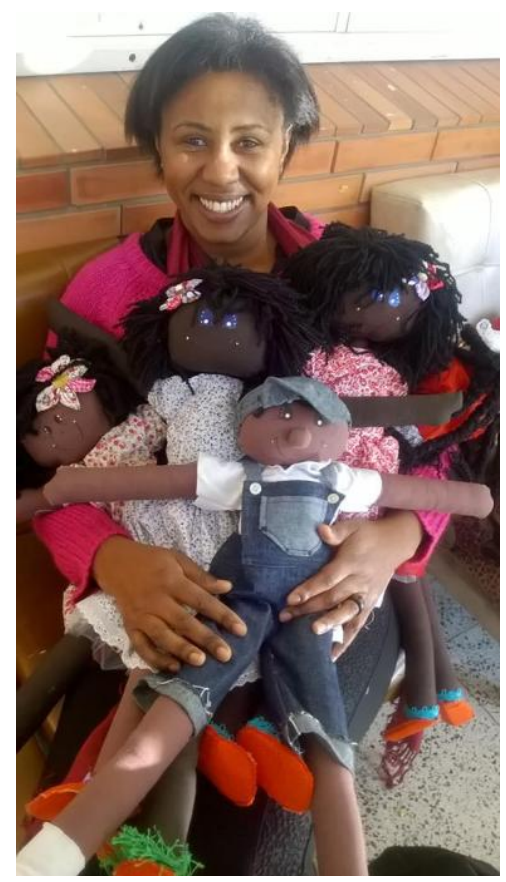


Figura III. Oficina de Bonecas Negras realizada na rede Básica de Ensino São Lourenço do Sul.

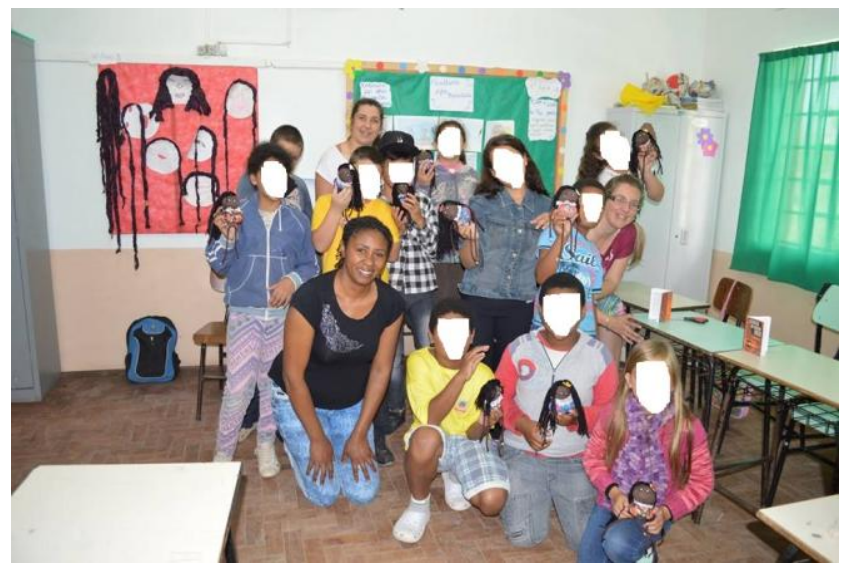

Figura IV. Oficina de Bonecas Negras realizada na Praça Dedé Serpa em São Lourenço do sul/RS.

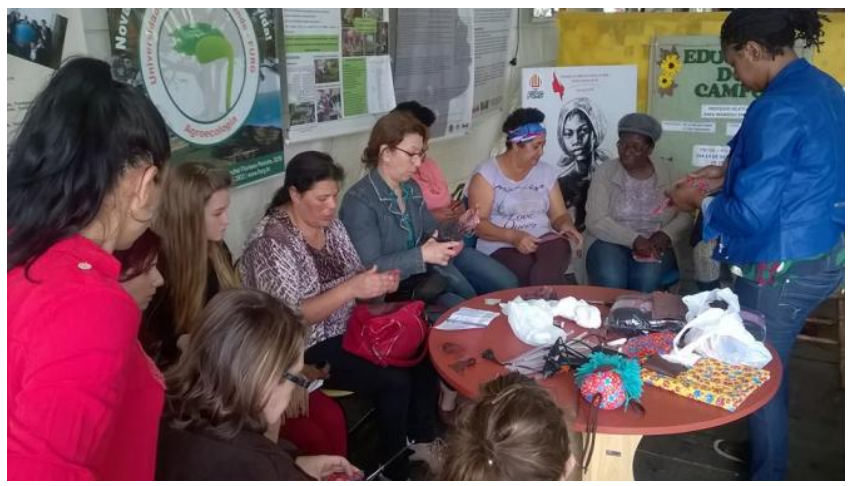

IMAGEM V: Oficina de Bonecas Negras realizada na Semana da Consciência Negra IFSUL/Camaquã/RS-2016.

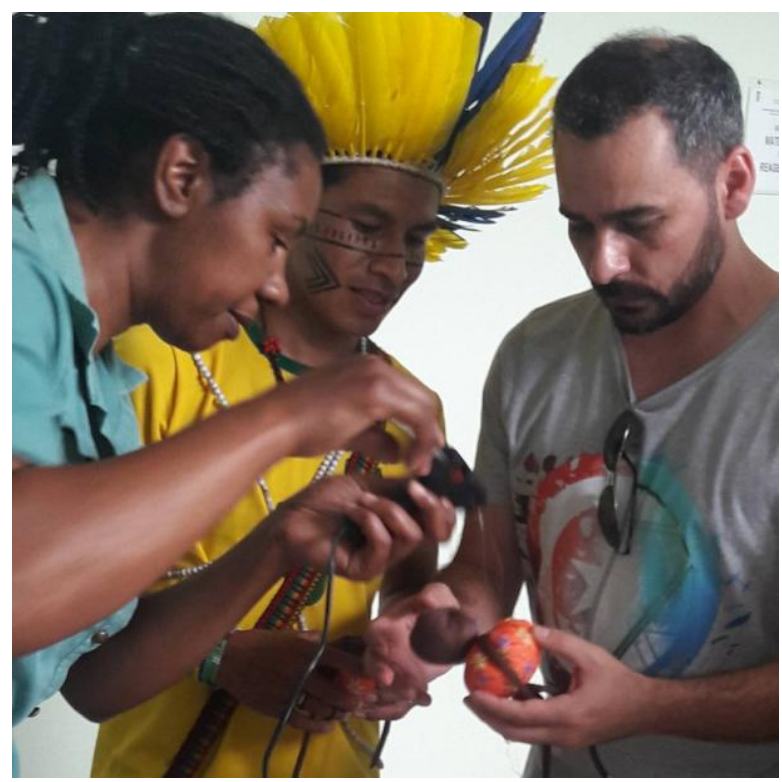


Como podemos perceber, tanto meninos quanto meninas têm confeccionado bonecas negras nas escolas e em práticas comunitárias na Educação do Campo. Inspiradas nos movimentos Feministas e Movimento Negro, essas oficinas têm garantido amplos debates na formação docente no campo da Educação do Campo e possibilitado pensar outras perspectivas metodológicas e outros sujeitos.

As formas de pensar os indígenas, negros, quilombolas, ribeirinhos, das florestas como as formas de pensar os trabalhadores dos campos e das cidades se articulam com as relações sociais, de produção, de trabalho, com o padrão de poder, dominação/subordinação a que esses coletivos foram subordinados (Arroyo, 2014, p. 4).

Assim, é possível questionar sobre as formas de subordinação, dominação e relações de poder com as oficinas de bonecas negras na Educação do Campo. Tais oficinas nos fazem (re)pensar sobre os métodos tradicionais de educação, e o quanto precisamos aprender a valorizar os saberes dos/as educandos/as em um movimento de construção do pensamento.

A descolonização, como sabemos, é um processo histórico: isto é, ela só pode ser compreendida, só tem a sua inteligibilidade, só se torna translúcida para si mesma na exata medida em que se discerne o movimento historicizante que lhe dá forma e conteúdo. A descolonização é o encontro de duas forças congenitalmente antagonistas, que têm precisamente a sua origem nessa espécie de substantificação que a situação colonial excreta e alimenta (Fanon, 2013, p. 52).

Nesse sentido, nossas aulas de Educação do Campo precisam se inspirar em epistemologias do campo latinoamericanas, que dialogam com os movimentos sociais, especialmente com os movimentos sociais do campo, reconhecendo e dialogando com a diversidade de povos tradicionais que temos na América Latina. É preciso reconhecer que "as lutas sociais formam os novos sujeitos sociais em cada espaço e em cada tempo da História e este é um processo cultural”. (Caldart, 2012, p. 79).

\section{Considerações finais}

É na não conclusão do ser, que se sabe como tal, que se funda a educação como processo permanente. Mulheres e homens se tornaram educáveis na medida em que se reconheceram inacabados. Não foi a educação que fez mulheres e homens educáveis, mas a consciência de sua inconclusão é que gerou sua educabilidade. É também na inconclusão de que nos tornamos conscientes e que nos inserta no movimento permanente de procura que se alicerça a esperança. Não sou esperançoso, disse certa vez, por pura teimosia, mas por existência antológica (Freire, 2014, p. 57).

Com essas palavras de Paulo Freire buscamos fazer algumas considerações que não findam com esse trabalho. 
Compartimos do sentimento de esperança, pois em uma sociedade que ainda busca anular a existência da diversidade e de sujeitos, é necessária muita esperança para seguir.

Vivemos em tempos de "escolas sem partidos", de tentativas de transformar a educação crítica, emancipatória e libertária em uma educação supostamente neutra. Neutra porque não reconhece em seu currículo e no cotidiano escolar a diversidade de sujeitos, e tampouco reconhece nos Direitos Humanos e nos Movimentos Sociais possibilidades de diálogos.

Vivemos tempos em que as Leis que garantiam a inserção da história afrobrasileira são negadas. Sabemos que por meio do processo educativo, cultural e científico buscou-se criar estratégias que envolvam de forma indissociável o ensino e a pesquisa de forma que viabilize a relação entre Universidade e Sociedade, mas tais práticas voltam a ser retiradas dos currículos escolares com o lema de uma suposta "educação neutra".

Com essa relação, que é de suma importância, busca-se desvelar alguns "pré-conceitos" com relação aos povos afrodescendentes, bem como trazer para a cena a cultura e a história desses povos, que fortalecidos com a Lei de $n^{\circ}$ $10.639 / 2003$ passaram a ter uma melhor visibilidade nos espaços escolares. Trata de uma Lei que obriga a realizar o estudo da Cultura Afro-Brasileira e Indígena nos diferentes níveis de ensino, e que garante que a educação não seja descompromissada e descomprometida com essa significativa parcela da população brasileira.

Esse tipo de prática faz parte de uma educação voltada para a cidadania e o respeito pelas diferenças. Trata de uma educação dialogada com as comunidades tradicionais, movimento de Consciência Negra, Movimento Negro e a população negra em geral.

Conhecer a luta dos negros e indígenas no Brasil, a história dos negros e dos indígenas, problematizar a cultura negro-brasileira e indianista e a importância de ambos na formação da sociedade brasileira é o mínimo que temos que ver em nossas escolas e outros espaços sociais e institucionais.

O resgate da contribuição desses povos nas áreas sociais, econômicas e políticas chega de forma estereotipada e repleta de preconceitos. Ainda são poucos educadores e educadoras que incluem os conteúdos referentes à história desses povos e suas culturas no currículo escolar. Acreditam que algumas áreas específicas devem se preocupar com essas questões. 
O parágrafo $2^{\circ}$ da Lei $\mathrm{n}^{\mathrm{o}} 11.645$, de 10 de março de 2008 diz que "os conteúdos referentes à história e cultura afro-brasileira e dos povos indígenas brasileiros serão ministrados no âmbito de todo o currículo escolar, em especial nas áreas de educação artística e de literatura e história brasileiras". Muitos professoras e professoras, acomodados/as nas suas especificidades, acreditam que essa inclusão não diz respeito a sua área, tampouco permitindo que essas questões sejam trabalhadas de maneira interdisciplinar.

Em cursos de formação pedagógica escutamos relatos de que no dia do índio e no dia 20 de novembro (Dia da Consciência Negra) instituições ainda obrigam a fazer alguma atividade relacionada às respectivas datas e registrar no diário de classe para cumprir a lei. Esse tipo de solução para o cumprimento da lei pode acarretar danos ainda maiores na formação de crianças, adolescentes e jovens no que diz respeito aos seus conhecimentos dessas culturas, por isso a importância de especialização e estudos por parte de quem educa, acerca das culturas indígenas e afro-brasileiras.

O dia da consciência negra e/ou o dia do índio, devem ser lembrados sim, mas essas datas devem compor uma proposta de currículo e de educação.
É preciso retomar o princípio freireano da não neutralidade, denunciar os índices de violência e as desigualdades sociais.

Os silenciados/as, excluídos/as ainda precisam ser incluídos/as no cotidiano escolar, em nossos planos de aulas e em nossas práticas escolares educativas e comunitárias. Somente assim a educação estará contribuindo para além de um currículo escolar que inclui a diversidade, mas uma sociedade com conhecimentos históricos capazes de interferir na realidade social dessas pessoas.

É emergente o questionamento na Educação do Campo do lugar dos povos tradicionais e inseri-los em nosso currículo, em nossas práticas escolares e comunitárias, fazendo com que os povos historicamente invisibilizados sejam protagonistas em espaços educativos. Seus saberes e suas práticas cotidianas precisam ser valorizadas e resgatadas na formação de professores e professoras do campo. Caso contrário, nossas práticas educativas continuarão sendo carregadas de preconceitos e silenciamentos.

Sendo assim, frente alguns avanços que tivemos, não é possível retroceder. A Educação Popular, as Epistemologias do Campo e os Estudos Feministas possuem uma intrínseca relação para a superação de opressão e pode, sim, contribuir para que 
ousemos trabalhar em nossas práticas escolares e comunitárias "outros sujeitos e outras pedagogias".

\section{Referências}

Arruti, J. M. (2005). Mocambo: Antropologia e história do processo de formação quilombola. Bauru. São Paulo: EDUSC.

Arroyo, M. (2014). Outros Sujeitos, Outras Pedagogias. Vozes: Petrópolis.

Brasil. Lei $\mathrm{n}^{\circ} 11.645$ (2008). Altera a Lei $n^{-}$9.394, de 20 de dezembro de 1996, modificada pela Lei $n^{-}$10.639, de 9 de janeiro de 2003, que estabelece as diretrizes e bases da educação nacional, para incluir no currículo oficial da rede de ensino a obrigatoriedade da temática "História e Cultura Afro-Brasileira e Indigena". Recuperado de: http://www.planalto.gov.br/ccivil_03/_ato2 007-2010/2008/lei/111645.htm.

Brasil. Lei $\mathrm{n}^{\circ}$. 10.639, de 9 de janeiro de 2003. (2003). Altera a Lei $n^{\circ} 9.394$, de 20 de dezembro de 1996, que estabelece as diretrizes e bases da educação nacional, para incluir no currículo oficial da Rede de Ensino a obrigatoriedade da temática "História e Cultura Afro-Brasileira", e dá outras providências. Recuperado de: http://www.planalto.gov.br.

Caldart, R. S. (2012). Pedagogia do Movimento. São Paulo: Expressão Popular.

Centro de Apoio ao Pequeno Agricultor (2010). Revelando os quilombos no Sul. Pelotas: Centro de apoio ao Pequeno agricultor.

Dutra, M. (2011) Direitos Quilombolas: Um estudo do impacto da cooperação ecumênica. Rio de Janeiro: Koinonia.
Fanon, F. (2013). Os condenados da Terra. Editora: UFJF. Juiz de Fora.

Ferreira, A. S. (2016). Relatos das oficinas de bonecas negras. Acervo do Núcleo de Estudos Afro brasileiro e Indígena da FURG, Campus São Lourenço do Sul, s/p.

Freire, P. (1979). Conscientização: Teoria e prática da libertação. São Paulo: Cortez e Moraes.

Freire, P. (2014) Pedagogia da Autonomia. Saberes necessários à Prática Educativa. Paz e Terra: Rio de Janeiro.

Kleba, M. E., \& Wendausen, A. (2009). Empoderamento: processo de fortalecimento dos sujeitos nos espaços de participação social e democratização política. Saúde \& Sociedade, 18(4), 733743.

Lagarde y de los Ríos, M. (2005) Los cautiverios de las mujeres: madresposas, monjas, putas, presas y locas. México: Universidade Nacional Autónoma de México.

Leite, I. B. (1999). Quilombos $e$ quilombos: cidadania ou folclorização. Horizontes Antropológicos/UFRGS. IFCH. Programa de Pós-Graduação em Antropologia Social. Porto Alegre: PAPGAS.

Linhares, L. F. R. (s/d). Comunidade Negra Rural: um velho tema, uma nova discussão. Disponível em: <http://www.nead.org.br/artigodomes $>$. Acesso Setembro/2016.

Macedo, A. G., \& Amaral, A. L. (2005). Dicionário da Crítica Feminista. Porto: Afrontamentos.

Matos, M. Z. T. (2004). Bonecas Negras Cadê? $O$ negro no currículo escolar: Sugestões e Práticas. Belo Horizonte: Maza Edições. 
Rosa, G. R. (2016). Educação e Direitos das Mulheres: resistências e subversão nas práticas educativas. In Machado, R. C. F., \& Castro, A. M. (Org.). Direitos das Mulheres no Brasil: Experiências de Norte a Sul. (pp. 49-68). Manaus: UEA Edições.

Saffioti, H. I. B. (2004). Gênero, patriarcado, violência. São Paulo: Fundação Perseu Abramo.

Saffioti, H. (1976). A mulher na sociedade de classes: mito e realidade. Prefácio de Antônio Cândido de Mello e Souza. Petrópolis: Vozes.

Soihet, R. (1997). História, mulheres, gênero: contribuição para um debate. In Aguiar, N. Gênero e ciências humanas: desafio às ciências desde a perspectiva das mulheres (pp. 95-114). Coleção Gênero. Rio de Janeiro: Rosa dos Tempos.

Recebido em: 16/10/2016

Aprovado em: 17/12/2016

Publicado em: 19/04/2017

Como citar este artigo / How to cite this article / Como citar este artículo:

APA:

Rosa, G. R., \& Ferreira, A. S. (2017). A confecção de bonecas negras na formação de professores. Rev. Bras. Educ. Camp., 2(1), 127-143.

ABNT:

ROSA, G. R.; FERREIRA, A. S. A confecção de bonecas negras na formação de professores. Rev. Bras. Educ. Camp., Tocantinópolis, v. 2, n. 1, p. 127-143, 2017. 